\title{
A sociologia, religiões e 0 protestantismo vivido
}

\section{Jalcione Almeida*}

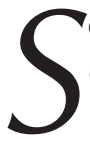

ociologias apresenta neste número aos seus leitores o tema da religião em uma análise sociológica singular, baseada no conceito de religião vivida (lived religion) (Ammerman, 2007; 2014; entre outros). O conjunto de artigos que compõe o dossiê, segundo seus organizadores Verónica Roldán e Rolando Pérez, destaca resultados de pesquisas realizadas em três cidades latino-americanas (Córdoba, Lima e Montevidéu) e em uma cidade do sul da Europa (Bilbao), colocando em evidência, do ponto de vista sociológico, a experiência religiosa, a vida cotidiana e os processos de autonomia e desinstitucionalização da vivência religiosa. As reflexões contidas nos artigos giram em torno das implicações da religiosidade vivida no protestantismo contemporâneo, reflexões que permitem olhar as interações, as

*Universidade Federal do Rio Grande do Sul (UFRGS), Porto Alegre, Brasil. 
narrativas e as práticas dos crentes vinculados ao protestantismo evangélico urbano em diálogo com os temas e dinâmicas da modernidade. $^{1}$

Mais detidamente, os trabalhos deste dossiê visam contribuir com o campo dos estudos sociológicos sobre a religião vivida, evidenciando o modo como os/as crentes, em um contexto de pluralização do campo religioso ${ }^{2}$, selecionam, adaptam, reinterpretam e se apropriam das práticas e narrativas religiosas no cotidiano. Sociologicamente, o que interessa nessas reflexões é o que parece central a outras no diversificado campo da sociologia das religiões, ou seja, analisar o papel fundamental que as religiões exercem na vida social, e também a relação entre os indivíduos e as instituições religiosas. No caso das abordagens contidas neste dossiê, é destacada a perspectiva de estudo da religiosidade "desde abajo" (Roldán; Perez, neste dossiê), tendentes a destacar as práticas cotidianas de "indivíduos comuns" e distantes das abordagens que focam a compreensão do fenômeno religioso a partir dos líderes e especialistas legitimados pelas instituições no campo religioso (Ammerman, 2007), ou por intermédio de perspectivas macrossociais.

A partir de seus marcos fundadores, ancorados em autores clássicos como Émile Durkheim, Karl Marx, Max Weber e Georg

\footnotetext{
${ }^{1}$ Segundo Morello (2017, p. 21), "o enfoque da religião vivida enfatiza a agência de atores, já que analisa o processo de sacralização em que os atores promovem rituais e símbolos, ou como os indivíduos em tempos particulares se utilizam de modismos religiosos particulares para expressar sua relação com o transcendente."

${ }^{2}$ Este pluralismo pode ser identificado não somente a partir de uma variedade de discursos e ritualidades, mas também na emergência de atores religiosos com atuação/agência em diversos campos sociais, criando estratégias de empoderamento e apropriação do espaço público. Para análises no contexto latino-americano, ver, entre outros, Panotto, 2012; Pérez, 2016; Wynarczyk, 2010.
} 
Simmel nas ciências sociais ${ }^{3}$, e outros como Sigmund Freud e William James, muitas e diversificadas são as abordagens sociológicas no tema das religiões que se interessam pela elaboração de teorias visando compreender aspectos da vida religiosa e sua influência nas sociedades. No caso brasileiro, é na segunda metade do século 20, rompendo com uma perspectiva psicológica e médica muito centrada em casos empíricos baseados em religiões afro-brasileiras, que os cientistas sociais passam a aprofundar suas observações e investir sua atenção em fenômenos religiosos a partir de uma perspectiva mais sociológica, entendendo a religião como um elemento essencial para a investigação do social (Augustin; Calgaro; Oliveira, 2010). ${ }^{4}$

A abordagem principal apresentada neste dossiê pode estabelecer diálogos críticos e frutíferos com algumas das abordagens clássicas e outras tantas mais contemporâneas. O campo empírico privilegiado no momento para este diálogo é aquele caracterizado pela mouvance recente denominada de "evangelismo político" e a crescente presença de seus atores em outros campos, como o da ação social, da economia, da política institucional e da cultura, como parece revelar o caso brasileiro atual, contexto sociocultural no qual até pouco tempo predominava o catolicismo e seus atores. Interessante notar, nesse aspecto, a diversidade de atores protestantes (no sentido amplo do termo) presentes em diversas instâncias da sociedade e do

\footnotetext{
${ }^{3}$ Para aqueles que se iniciam neste tema, sugere-se, entre outros, o texto bem acessível e didático de Costa (2017).

${ }^{4}$ Entretanto, é necessário ressaltar que a transição da primeira para segunda metade do século 20, destacando-se os anos 1950-60, foi marcada por estudos que aprofundaram a realidade brasileira, que passava por um processo de industrialização e urbanização, ficando o tema da religião um pouco à margem do foco dos cientistas sociais.
} 
Estado, propondo pautas de discussão, intervindo no debate e na construção de políticas ou agendas públicas.

Os artigos deste dossiê, em suma, enquadram-se no leque das novas perspectivas e influências nos estudos sociológicos sobre as religiões, em uma tentativa de reorientar os enfoques sobre o social. Essa abordagem pretende expandir o conhecimento sobre o social, questionando as abordagens globalizantes do real e permitindo, assim, o questionamento dos discursos. A abordagem mais microssocial das religiões, aqui apresentada e debatida, tende a dinamizar as relações sociais na medida em que influencia a abertura de perspectivas e diversifica as representações, abrindo-se ao simbólico e ao cotidiano. Ademais, ela busca preservar especificidades sociais e priorizar compreensões mais aguçadas das interações sociais. Essa abordagem também se apresenta ao diálogo com outras perspectivas sociológicas no campo dos estudos sobre as religiões. O debate crítico certamente é muito bem-vindo.

Este número de Sociologias também conta com mais quatro artigos, uma resenha e duas comunicações de pesquisa que inauguram uma nova seção da revista: a Brazil today. O primeiro artigo apresentado é de autoria de Georges Gérard Flexor, Adrianno Oliveira Rodrigues e Robson Dias da Silva, intitulado "Religião e preferências econômicas e políticas entre jovens universitários da periferia: um estudo exploratório na Baixada Fluminense", e procura analisar a importância da religião nas preferências políticas, sociais e econômicas entre jovens universitários da periferia do Rio de Janeiro. Os dados são oriundos da aplicação de um survey que recolheu opiniões de estudantes dos cursos de graduação de um campus da Universidade Federal Rural do Rio de Janeiro (UFRRJ), localizado em Nova Iguaçu, na baixada fluminense. A análise multivariada 
de componentes principais, clusters kmeans e regressão dos dados do survey destaca a influência significativa das igrejas evangélicas em diversos assuntos de cunho moral. A pesquisa também identifica uma ampla e difusa demanda por políticas sociais e melhor provisão de bens públicos como saúde e educação.

O segundo artigo, "Tendências ocupacionais no Exército Brasileiro (1998-2012)”, de autoria de Frederico Carlos de Sá Costa, analisa a profissionalização militar a partir da hipótese de que uma tendência recente (no período que o título do artigo anuncia) mostra que as vagas oferecidas ao final do primeiro ano da Academia Militar das Agulhas Negras (AMAN) são preenchidas no Quadro de Material Bélico e do Serviço de Intendência. Segundo o autor, na gênese deste fenômeno está a transformação da visão que o oficial tem do Exército Brasileiro, de instituição para organização. Sublinhando a análise tem-se a expectativa de desempenho da função militar no Brasil, a orfandade e a profissionalização militares. A proposta teórica utilizada para a compreensão dos dados que indicam a preferência dos cadetes mais antigos pelo Quadro de Material Bélico e pelo Serviço de Intendência é a institucional/ocupacional. O desdobramento da hipótese do autor é a de que, no período considerado, os cadetes mais antigos tendem a encarar a carreira no Exército como um emprego como outro qualquer.

Elier González-Martínez e Belkis Rojas Hernández, no artigo "Validación de una escala de mediaciones culturales en el contexto de proyectos socioculturales comunitarios", tomam por objeto de estudo os projetos socioculturais comunitários que se utilizam de expressões artísticas para promover o desenvolvimento das comunidades e aprimorar a qualidade de vida de seus integrantes. A investigação realizada objetivou criar e validar uma escala que permita analisar e compreender as formas de ação 
e manifestação dessas mediações culturais em comunidades. O instrumento proposto, composto por cinco dimensões estética, artística, participativa, axiológica e ancoragem territorial -, responde a um conceito de mediações culturais manifestado na construção, reprodução e intercâmbio simbólico produzido entre os fatores culturais, os dispositivos artísticos, o território e o público participante em projetos socioculturais comunitários. Dos itens propostos para cada dimensão resultou a análise de diferentes grupos focais com especialistas na temática e de validação de especialistas por meio do método Delphi. A análise fatorial evidenciou a correlação entre todas as dimensões.

O último artigo, "Trazendo os governos de volta: a chefia do executivo e os resultados do ativismo institucional LGBT (20032014)", de autoria de Matheus Mazzilli Pereira, apresenta uma análise comparada da trajetória e dos resultados do ativismo institucional LGBT em quatro órgãos do Poder Executivo no nível federal entre 2003 e 2014. Os resultados da análise indicam, em primeiro lugar, que, apesar de suas distintas trajetórias e configurações em relação ao ativismo LGBT, tais órgãos apresentaram uma queda semelhante nos resultados produzidos por burocratas ativistas a partir do primeiro Governo Dilma. Em segundo lugar, indicam que, a partir desse período, a chefia do Executivo passou a intervir de forma semelhante em diferentes ministérios e secretarias, criando obstáculos comuns à ação dos ativistas LGBT neles inseridos. Assim, o autor argumenta que os resultados do ativismo institucional são também condicionados pelas intervenções realizadas pela chefia do Executivo em seus ministérios e secretarias, tornando-se necessário "trazer os governos de volta" à análise das relações entre movimentos sociais e o Estado no Brasil.

Na seção Resenhas, Ângela Camana apresenta e discute o livro de Isabelle Stengers "Civiliser la modernité? Whitehead 
et les ruminations du sens commun", publicado em 2017 pela editora Les Presses du Réel (Dijon, França). Nesta obra, Stengers retoma mais uma vez as contribuições da filosofia processual de Alfred North Whitehead para discutir a produção de conhecimento na modernidade, tema proeminente da vasta obra - e pouco traduzida ao português - da filósofa belga. Em diálogo com pensadores contemporâneos, como Anna Tsing, Bruno Latour e Donna Haraway, a resenhista nos convoca a ponderar o que podem as Humanidades conhecer frente às contingências e incertezas de nosso tempo. A resenha busca explorar, sobretudo, as potenciais contribuições desta obra para as ciências sociais, articulando a discussão filosófica e seus desdobramentos metodológicos.

Por fim, a revista apresenta as primeiras comunicações de pesquisa da nova seção Brazil today, na qual se publica textos em inglês de pesquisas e análises brasileiras que são pertinentes à compreensão dos aspectos sociais de questões relevantes do Brasil atual, tais como aquelas referentes às instituições democráticas, violência, crime organizado, direitos humanos, direitos sociais, meio ambiente, povos originários, desigualdade social, minorias e racismo, racismo e sexualidades, movimentos sociais e formas de participação social, consequências dos novos meios de comunicação, problemas de integração nacional, políticas de desenvolvimento, memória social, religiões, educação, saúde e questões urbanas e rurais.

A seção aceita textos, acessíveis a não especialistas, de duas a quatro páginas, em português, que serão traduzidos pela revista. As contribuições devem deixar clara a contribuição das pesquisas para o entendimento do Brasil atual. As contribuições de especialistas de outras áreas afins também são bem-vindas, desde que salientem os aspectos sociais das questões abordadas. Não são aceitos resumos de pesquisas puramente teóricas, 
técnicas ou focadas principalmente em outros países ou outros períodos históricos.

A primeira comunicação apresentada, de Carolina Dantas Figueiredo e Eduardo Amorim, intitulado "Os silêncios e a cobertura midiática da Copa do Mundo em Pernambuco, Brasil", referem a Copa do Mundo de 2014 e o período de grandes turbulências políticas e mudanças no mercado de comunicação. A partir do olhar de quem atuou na cobertura desse evento, os autores apresentam as principais conclusões de uma dissertação que analisa as formas de silenciamento que vêm sendo empregadas na contemporaneidade pelas mídias de massa tradicionais.

Breno Augusto Souto Maior Fontes é responsável pela segunda comunicação de pesquisa, "Redes, sociabilidades e saúde: o lugar da atenção à saúde mental no Brasil", no qual objetiva apresentar um resumo das atividades de pesquisa desenvolvidas há alguns anos sobre saúde mental e sociabilidades observadas nas redes de atenção à saúde mental em cidades brasileiras, apresentando os principais resultados destas pesquisas realizadas durante a década de 2010.

Desejamos a todos uma boa leitura.

O Editor 


\section{Referências}

1. AMMERMAN, Nancy T. Everyday religion. Observing modern religious lives. New York: Oxford University Press, 2007.

2. AMMERMAN, Nancy T. Sacred stories, spiritual tribes. Finding religion in everyday life. New York: Oxford University Press, 2014.

3. AUGUSTIN, Roberta L.; CALGARO, Cleide; OLIVEIRA, Sandra M. de. Uma reflexão sobre a religião como objeto de estudo nas ciências sociais no Brasil. In: II Encontro Internacional de Ciências Sociais: as ciências sociais e os desafios para o século XXI. Anais... Pelotas, 2010. Disponível em: https://ambitojuridico.com. br/edicoes/revista-80/uma-reflexao-sobre-a-religiao-como-objeto-de-estudo-nasciencias-sociais-no-brasil/

4. COSTA, Waldney de S. R. Religião na perspectiva sociológica clássica: considerações sobre Durkheim, Marx e Weber. Sacrilegens, v. 14, n. 2, p. 03-24, jul.-dez, 2017.

5. MORELLO, Gustavo. Lived religion in Latin America and Europe: Roman Catholics and their practices. Quaderni del Csal 4, v. 9, n. 17, núm. esp., p. 1323, 2017.

6. PANOTTO, Nicolás. Los evangélicos y lo político: análisis histórico y nuevos acercamientos. Praxis Evangélica, n. 20, p. 105- -119, 2012.

7. PÉREZ, Rolando. Las apropiaciones religiosas de lo público: el caso de los evangélicos en el Perú. In: ROMERO, Catalina (Ed.). Diversidad religiosa en el Perú. Miradas múltiples. Lima: Fondo Editorial de la PUCP/CEP, 2016.

8. ROLDÁN, Verónica; PÉREZ, Rolando. El protestantismo vivido: un estudio comparativo desde América Latina y el sur de Europa. Sociologias, v. 22, n. 53, p. 20-35, 2020. http://dx.doi.org/10.1590/15174522-99908

9. WYNARCZYK, Hilario. Sal y luz a las naciones. Evangélicos y política en la Argentina (1980-2001). Buenos Aires: Instituto Di Tella; Siglo XXI Iberoamericana, 2010. 